\title{
METODE NuMERIK STEPEST DESCENT TERINDUKSI NEWTON \\ DALAM PEMECAHAN MASAlah OPTIMISASI TANPA KENDAla
}

\section{INDUCTED NEWTON STEEPEST DESCENT AS A NUMERICAL METHOD TO SOLVE OPTIMIZATION PROGRAM WithouT CONSTRAIN}

\author{
Rukmono Budi Utomo \\ Universitas Muhammadiyah Tangerang \\ Tanggerang, Indonesia \\ Rukmono.budi.u@mail.ugm.ac.id
}

\begin{abstract}
Abstrak
Penelitian teoritis ini mengkaji mengenai metode numerik Stepest Descent yang terinduksi Newton. Penelitian ini dilakukan dengan cara memahami terlebih dahulu mengenai metode numerik Stepest Descent dan Newton, kemudian mengkonstruksi metode baru yang disebut dengan Stepest Descent terinduksi Newton. Pada makalah ini turut disertakan pula contoh perhitungan numerik antara ketiga metode tersebut beserta analisis perhitungannya.

Kata Kunci: Metode Stepest Descent, Newton, Metode Stepest Descent terinduksi Newton

Abstract

This research is investigating numerical method of Steepest Descent inducted of Newton. Steps of this research can be described as follows: First, the author has to understand the definition and algorithm of Steepest Descent and Newton methods. After that, the second, author constructing the new method called by Steepest Descent inducted newton. In this paper, author also containing examples of numerical counting among that three methods and analyze them self.
\end{abstract}

Keyword: Steepest Descent, Newton, Steepest Descent Inducted Newton.

\section{Pendahuluan}

Tidak selamanya solusi analitik dari suatu permasalahan matematika khususnya optimisasi dapat ditemukan. Terkadang ditemukan kendala yang cukup rumit sehingga solusi analitik tidak mudah ditemukan. Berdasarkan hal tersebut solusi numerik merupakan sesuatu hasil yang cukup realistis untuk dicari meski hasilnya merupakan hampiran. Metode numerik merupakan suatu metode pendekatan (approximation) dari solusi sejati, dan karenanya terdapat besarnya angka kesalahan (eror) yang dihasilkan oleh perhitungan numerik [1]. Kesalahan ini lebih sering diakibatkan baik karena pemotongan suku atau pembulatan nilai.

Masalah optimisasi merupakan persoalan yang banyak menggunakan metode numerik dalam mencari solusi penyelesaian tatkala solusi analitik sulit ditemukan. Menurut kendalanya (constrain), masalah optimisasi dibagi 2 yakni masalah optimisasi dengan kendala dan tanpa kendala, sedangkan menurut variabel bebasnya masalah optimisasi juga dibagi atas dua, yakni masah optimisasi dengan 1 varibel bebas dan banyak variabel bebas Metode numerik untuk menyelesaikan masalah optmisasi dengan 
kendala dapat menggunakan metode Kuhn-Tucker, sedangkan untuk masalah optimisasi tanpa kendala dengan 1 variabel bebas dapat menggunakan metode Golden Rasio, Fibonacci, Biseksi, Dichotomus dan Secant. Lebih lanjut untuk menyelesaikan masalah optmisasi dengan lebih dari 1 variabel bebas dapat menggunakan metode Aksial, Newton, Hook and Jeeves, Stepest Descent, Arah Konjugasi, dan Roosenberg [2].

Makalah ini membahas mengenai metode numerik Steepest Descent yang terinduksi newton. Penelitian dilakukan dengan memahami terlebih dahulu mengenai metode numerik Steepest Descent dan Newton kemudian memformulasikan metode baru yang disebut dengan metode Steepest Descent terinduksi Newton. Dalam makalah ini juga akan diberikan contoh perhitungan numerik untuk ketiga metode tersebut beserta analisisnya.

\section{KajIAN TeORI}

\section{A. Definisi Ruang Vektor}

Himpunan tak kosong $V$ merupakan ruang vektor apabila $\forall x, y, z \in V$ dan $a, b \in R$ sedemikian hingga memenuhi aksioma-aksioma sebagai berikut: [3]

$$
\begin{aligned}
\text { i. } & x+y \in V \\
\text { ii. } & x+y=y+x \\
\text { iii. } & (x+y)+z=x+(y+z) \\
\text { iv. } & \exists 0 \in V \quad \ni 0+V=V+0=0 \\
\text { v. } & \exists-x \in V \quad \ni x+(-x)=0 \\
\text { vi. } & a x \in V \\
\text { vii. } & a(x+y)=a x+a y \\
\text { viii. } & (a+b) x=a x+b x
\end{aligned}
$$

ix. $\quad(a b) x=a(b x)$

x. $\quad 1 x=x$

\section{B. Definisi Norm}

Diberikan $X, Y$ sembanrang dua buah vektor. Sembarang bilangan riil $\|X\|$ dinamakan norm dari $X$ apabila memenuhi aksioma-aksioma sebagai berikut:

i. $|X| \mid \leq 0$

ii. $\quad \mid a X \|=0 \leftrightarrow X=0$

iii. $\quad\|a X\|=|a|\|X\|, a \in R$

iv. $\quad \mid X+Y\|\leq\| X\|+\| Y \|$

\section{Definisi Kombinasi Linear [3]}

Misalkan $X_{i}, 1 \leq i \leq m$ vektor-vektor di $V$ maka $X$ disebut kombinasi linear dari vektor-vektor $X_{i}$ jika $X=\sum_{i=1}^{m} a_{i} X_{i}$

\section{Definisi Bebas Linear [3]}

Vektor $X_{i}, \quad 1 \leq i \leq m$ anggota-anggota $V$ disebut tak bebas linear jika dan hanya jika terhadap bilangan-bilangan riil tak semuanya nol sedemikian hingga $\sum_{i=1}^{m} a_{i} X_{i}=0$. Apabila pembuat nol hanya $a_{i}=0$, maka vektor-vektor tersebut dikatakan bebas linear.

\section{E. Definisi Hubungan Vektor [2]}

Diberikan dua buah vektor $X, Y$ dengan $\quad X=\left\{x_{1}, x_{2}, \ldots, x_{n}\right\} \quad$ dan $Y=\left\{y_{1}, y_{2}, \ldots, y_{n}\right\} . \quad$ Pernyataan berikut adalah benar 
i. $X=Y$ jika dan hanya jika $x_{i}=y_{i}$ $\forall i, i=1,2, \ldots, n$

ii. $X<Y$ jika dan hanya jika $x_{i}<y_{i}$ $\forall i, i=1,2, \ldots, n$

iii. $X>Y$ jika dan hanya jika $x_{i}>y_{i}$ $\forall i, i=1,2, \ldots, n$

\section{F. Definisi Bola Terbuka [2]}

Diberikan $X_{0} \in \mathbb{R}^{n} \quad$ serta $\quad \rho>0$. Himpunan $\quad B\left(x_{0}, \rho\right)=\left\{x \in \mathbb{R}^{n} \mid \| x_{0}-\right.$ $x \|<\rho\}$ merupakan persekitaran $\rho$ dari $x_{0}$ atau disebut bola terbuka dengan pusat $x_{0}$ dan radius $\rho$.

\section{G. Definisi Titik Dalam [4]}

Titik $x_{0} \in X \subseteq \mathbb{R}^{n}$ disebut titik dalam (interior point) dari himpunan $X$ jika $\exists \delta>0$ sehingga $B\left(x_{0}, \delta\right) \subseteq X$

\section{H. Definisi Titik Batas [4]}

Titik $x_{0} \in X \subseteq \mathbb{R}^{n}$ disebut titik batas (boundary point) dari himpunan $X$ jika setiap sekitar $\rho$ dari $x_{0}$ memuat beberapa titik yang berada di $X$ dan beberapa titik yang tidak berada di $X$.

\section{Definisi Komplemen [4]}

Jika $X \in \mathbb{R}^{n}$, maka himpunan $\mathbb{R}^{n}-X$ yang memuat semua titik-titik yang ada di $\mathbb{R}^{n}$ namun tidak dari $X$ disebut komplemen dari $X$.

\section{J. Definisi Himpunan Tertutup [5]}

Himpunan $X$ disebut himpunan terbuka jika setiap titik dari $X$ merupakan titik interior dari $X$. Lebih lanjut himpunan $Y$ merupakan himpunan tertutup jika komplemen dari himpunan terbuka.

\section{K. Definisi Terbatas Ke Atas [5]}

Himpunan $S$ dikatakan terbatas ke bawah jika $y \in \mathbb{R}^{n}$ dengan semua komponennya berhingga sedemikian sehingga $\forall x \in S, y \leq x$, sebaliknya $S$ dikatakan terbatas ke atas.

\section{Definisi Bentuk Kuadratik [5]}

$$
\begin{aligned}
& F(X)=c_{11} x_{1}^{2}+c_{2} 2 x_{2}^{2}+\ldots+c_{n n} x_{n}^{2}+c_{12} x_{1} x_{2} \\
& +c_{1,3} x_{1} x_{3}+\ldots+c_{23} x_{2} x_{3}+\ldots
\end{aligned}
$$

dengan $c_{i j} \in R, 1 \leq i, \quad j \leq n$ disebut fungsi bentuk kuadratik dengan $n$ variabel $x_{1}, x_{2}, \ldots, x_{n}$

\section{Definisi Kondisi Kuadratik [6]}

Bentuk kuadratik $X^{t} A X$ disebut positif (negatif) definit jika $X^{t} A X>(<) 0$ untuk semua $X \neq 0$ dan terdapat sekurangnya satu vektor tak nol sedemikian hingga $X^{t} A X=0$.

Apabila tidak memenuhi keduanya, maka bentuk kuadratik tersebut dikatakan indefinite.

\section{N. Definisi Minimum Global [6]}

Fungsi $\quad F(x)$ dikatakan memiliki minimum global di $x_{0}$ dalam $S$ jika $f(x) \geq f\left(x_{0}\right)$

\section{O. Definisi Minimum Lokal [6]}

Fungsi $\quad F(x)$ dikatakan memiliki minimum lokal (relatif) di $x_{0}$ dalam $S$ jika terdapat sekitar $\delta$ dari $x_{0}$ 
sedemikian hingga $f(x) \geq f\left(x_{0}\right)$ untuk setiap $x$ di dalam persekitaran tersebut.

\section{P. Definisi Deret Taylor [1]}

Deret Taylor untuk fungsi $F(X)$ dengan $\quad X=\left\{x_{1}, x_{2}, \ldots, x_{n}\right\}$ didefinisikan sebagai

$$
F(X+\Delta x)=F(X)+\nabla F(X) \Delta X+\frac{(\Delta x)}{2} H(X)(\Delta x)+\vartheta_{3}
$$

dengan $\vartheta_{3}$ merupakan suku berderajat besar, dan $H(X)$ matrik Hessian yang didefinisikan sebagai

$$
H=\left[\begin{array}{cccc}
\frac{\partial^{2} F}{\partial x_{1}^{2}} & \frac{\partial^{2} F}{\partial x_{1} x_{2}} & \cdots & \frac{\partial^{2} F}{\partial x_{1} x_{n}} \\
\frac{\partial^{2} F}{\partial x_{2} x_{1}} & \frac{\partial^{2} F}{\partial x_{2}{ }^{2}} & \cdots & \frac{\partial^{2} F}{\partial x_{2} x_{n}} \\
\cdots \cdots & \cdots & \cdots & \cdots \\
\frac{\partial^{2} F}{\partial x_{n} x_{1}} & \frac{\partial^{2} F}{\partial x_{n} x_{2}} & \cdots & \frac{\partial^{2} F}{\partial x_{n}{ }^{2}}
\end{array}\right]
$$

Syarat perlu agar $X$ merupakan titik ekstrim dari fungsi $F(X)$ adalah $\nabla F(X)=0$ dengan $\nabla F(X)$ didefinisikan sebagai $\nabla F(X)=\left(\frac{\partial F}{\partial x_{1}}, \frac{\partial F}{\partial x_{2}}, \ldots, \frac{\partial F}{\partial x_{n}}\right)$

\section{Q. Algoritma Stepest Descent [7]}

Diberikan

$Z=F(X)=F\left(x_{2}, x_{2}, ., x_{n}\right) \quad$ dan $\quad$ akan ditentukan nilai $X=\left\{x_{1}, x_{2}, ., x_{n}\right\} \quad$ yang meminimalkan fungsi $F(X)$ tersebut.

i. Ambil $X_{1}=\left\{x_{1}, x_{2}, . ., x_{n}\right\} \in R^{n}$ sembarang titik awal dan ò>0 0 suatu konstanta positif yang menyatakan besarnya kesalahan eror yang ditoleransi. ii. Dibentuk $\nabla Z(X)=\left[\frac{\partial Z}{\partial x_{1}}, \frac{\partial Z}{\partial x_{2}}, \ldots, \frac{\partial Z}{\partial x_{n}}\right]$ gradient fungsi $Z$ saat $X_{1}$, kemudian tentukan untuk $\nabla Z\left(X_{1}\right)$ serta lakukan untuk $\nabla Z\left(X_{k}\right)$

iii. Jika $\left\|\nabla Z\left(X_{k}\right)\right\|<\varepsilon$, maka iterasi berhenti, sebaliknya iterasi dilanjutkan iv. Cari $\lambda_{k}$ dengan cara mencari titik ekstrim $Z\left(X_{k}+\lambda_{k} d_{k}\right)$ yakni dengan cara menderivatifkan fungsi $Z\left(X_{k}+\lambda_{k} d_{k}\right)$ dan menyamadengankan nol dengan arah pencarian $d_{k}=-\nabla Z\left(X_{k}\right)$

v. Nilai $X_{k}$ ditentukan dengan $X_{k}=X_{k-1}+\lambda_{k-1} d_{k-1}$

\section{R. Algoritma Newton [7]}

Tahapan-tahapan dalam metode Newton analog dengan Stepest Descent, yakni diberikan fungsi $Z=F(X)=F\left(x_{2}, x_{2}, ., x_{n}\right)$ dan akan ditentukan nilai $X=\left\{x_{1}, x_{2}, ., x_{n}\right\}$ yang meminimalkan fungsi $F(X)$ tersebut. Lakukan langkah i sampai iii dalam Stepest Descent, namun Nilai $X_{k}$ adalah $X_{k}=X_{k-1}+\left(-H\left(X_{k-1}\right)^{-1} \nabla Z\left(X_{k-1}\right)\right)$ dengan $H\left(X_{k-1}\right)^{-1}$ merupakan invers metrik Hessian ketika $X_{k-1}$. Lebih lanjut iterasi berhenti ketika $\left\|\nabla Z\left(X_{k}\right)\right\|<\varepsilon$.

\section{Pembahasan}

Berdasarkan algoritma Stepest Descent dan Newton, akan dikembangkan suatu 
metode baru yang disebut Metode Stepest Descent terinduksi Newton.

\section{A. Algoritma Stepest Terinduksi Newton}

Descent

Diberikan

$Z=F(X)=F\left(x_{2}, x_{2}, ., x_{n}\right)$ dan fungsi

ditentukan $X=\left\{x_{1}, x_{2}, ., x_{n}\right\}$ akan meminimalkan fungsi $F(X)$ tersebut.

i. Ambil $X_{1}=\left\{x_{1}, x_{2}, ., x_{n}\right\} \in R^{n} \quad$ titik sembarang titik awal dan ò $>0$ suatu konstanta positif yang menyatakan besarnya kesalahan eror yang ditolerasnsi.

ii. Dibentuk $\nabla Z(X)=\left[\frac{\partial Z}{\partial x_{1}}, \frac{\partial Z}{\partial x_{2}}, \ldots, \frac{\partial Z}{\partial x_{n}}\right]$

Tentukan untuk $\nabla Z\left(X_{1}\right)$ serta $\nabla Z\left(X_{k}\right)$

iii. Jika $\left\|\nabla Z\left(X_{k}\right)\right\|<\varepsilon$, maka iterasi berhenti, sebaliknya iterasi dilanjutkan.

iv. Cari $\lambda_{k}$ dengan cara mencari titik ekstrim fungsi $Z\left(X_{k}+\lambda_{k} d_{k}\right)$ yakni dengan cara menderivatifkan fungsi $Z\left(X_{k}+\lambda_{k} d_{k}\right)$ dan menyama- dengankan nol dengan arah pencarian $d_{k}=-H\left(X_{k-1}\right)^{-1} \nabla Z\left(\overline{X_{k-1}}\right)$

\section{B. Contoh Numerik 1}

Tentukan nilai $X=\left\{x_{1}, x_{2}\right\} \quad$ yang meminimalkan $Z\left(x_{1}, x_{2}\right)=2 x_{1}^{2}+x_{2}^{2}-3 x_{1}-x_{2}$ dengan menggunakan metode Stepest Descent dan Newton dengan toleransi kesalahan $\mathrm{o}=0.03$

\section{Solusi dengan Stepest Descent}

Ambil sebarang titk awal $X_{1}=\left\{-1, \frac{1}{2}\right\} \in R^{2}$. Berdasarkan masalah optimisasi di atas dapat ditentukan $\nabla Z\left(X_{1}\right)=[-7,0] . \quad$ Karena norm $\left\|\nabla Z\left(X_{1}\right)\right\|=7>\varepsilon$ maka iterasi dilanjutkan. Arah pencarian $d_{1}=-\nabla Z\left(X_{1}\right)=[7,0]$ dan berdasarkan hal tersebut dapat diperoleh $\lambda_{1}=\frac{1}{4}$. Apabila dicari, maka diperoleh nilai $X_{2}=\left\{\frac{3}{4}, \frac{1}{2}\right\}$ dengan $\nabla Z\left(X_{2}\right)=[0,0]$ dan $\left\|\nabla Z\left(X_{2}\right)\right\|=0<\varepsilon$.

Iterasi berhenti sehingga nilai $X=\left\{x_{1}, x_{2}\right\}$ yang meminimalkan masalah optimisasi di atas adalah $X_{2}=\left\{\frac{3}{4}, \frac{1}{2}\right\}$. Karena $\quad\left\|\nabla Z\left(X_{2}\right)\right\|=0 \quad$ hal ini mengindikasikan bahwa solusi numerik ini sama dengan solusi analitiknya.

\section{Solusi dengan Newton}

Ambil sebarang titk awal $X_{1}=\left\{-1, \frac{1}{2}\right\} \in R^{2}$. Berdasarkan masalah optimisasi di atas dapat ditentukan $\nabla Z\left(X_{1}\right)=[-7,0]$. Karena norm $\left\|\nabla Z\left(X_{1}\right)\right\|=7>\varepsilon \quad$ maka iterasi dilanjutkan.Dibentuk matriks Hessian $H=\left[\begin{array}{ll}4 & 0 \\ 0 & 2\end{array}\right]$. Berdasarkan hal tersebut $H\left(X_{1}\right)=\left[\begin{array}{ll}4 & 0 \\ 0 & 2\end{array}\right]$ dan $\quad H\left(X_{1}\right)^{-1}=\left[\begin{array}{cc}\frac{1}{4} & 0 \\ 0 & \frac{1}{2}\end{array}\right]$.

Berdasarkan hal diatas akan diperoleh

$$
-H\left(X_{1}\right)^{-1} \nabla Z\left(X_{1}\right)=\left[\frac{7}{4}, 0\right] \text {. Dengan }
$$

cara yang sama dapat dicari $X_{2}=\left\{\frac{3}{4}, \frac{1}{2}\right\}$ dengan nilai gradien $\nabla Z\left(X_{2}\right)=[0,0]$ dan $\left\|\nabla Z\left(X_{1}\right)\right\|=0<\varepsilon$.Iterasi berhenti sehingga 
nilai $X=\left\{x_{1}, x_{2}\right\}$ yang meminimalkan masalah optimisasi di atas adalah $X_{2}=\left\{\frac{3}{4}, \frac{1}{2}\right\}$. Dari solusi yang diperoleh melalui Stepest Descent dan Newton dengan pengambilan titik awal $X_{1}$ yang sama akan menghasilkan solusi numerik yang identik dengan solusi analitik.

\section{E. Solusi dengan Stepest Descent Terinduksi Newton}

Ambil sebarang titik awal $X_{1}=\left\{-1, \frac{1}{2}\right\} \in R^{2}$. Berdasarkan masalah optimisasi di atas dapat ditentukan $\nabla Z\left(X_{1}\right)=[-7,0]$. Karena nilai norm $\left\|\nabla Z\left(X_{1}\right)\right\|=7>\varepsilon$ maka iterasi dilanjutkan. Arah pencarian

$d_{1}=-H\left(X_{1}\right)^{-1} \nabla Z\left(X_{1}\right)=\left[\frac{7}{4}, 0\right]$

dengan demikian diperoleh $\lambda_{1}=\frac{35}{49}$. Berdasarkan hal tersebut diperoleh $X_{2}=\left\{\frac{3}{4}, 1\right\} \cdot$ dengan $\nabla Z\left(X_{2}\right)=[0,1]$.

Karena $\left\|\nabla Z\left(X_{2}\right)\right\|=1>\varepsilon$, maka iterasi dilanjuttkan. Dengan analog diperoleh $H\left(X_{2}\right)=\left[\begin{array}{ll}4 & 0 \\ 0 & 2\end{array}\right] \quad \operatorname{dan} H\left(X_{1}\right)^{-1}=\left[\begin{array}{cc}\frac{1}{4} & 0 \\ 0 & \frac{1}{2}\end{array}\right]$ dengan $-H\left(X_{2}\right)^{-1} \nabla Z\left(X_{2}\right)=\left[0, \frac{1}{2}\right]^{t}$.

Berdasarkan hal tersebut diperoleh $\lambda_{2}=-1$ dan $X_{3}=\left\{\frac{3}{4}, \frac{1}{2}\right\}$ dengan gradien $\nabla Z\left(X_{3}\right)=[0,0]$ dan norm $\left\|\nabla Z\left(X_{3}\right)\right\|=0<\varepsilon$. Karena $\left\|\nabla Z\left(X_{3}\right)\right\|=0<\varepsilon, \quad$ maka iterasi berhenti sehingga solusi nilai $X=\left\{x_{1}, x_{2}\right\}$ yang meminimalkan masalah optimisasi di atas adalah $X_{3}=\left\{\frac{3}{4}, \frac{1}{2}\right\}$. Berrdasarkan hal di atas pula, maka solusi numerik dalam solusi ini identic dengan solusi analitiknya.

\section{F. Contoh Numerik 2}

Pandang kembali contoh numerik 1 . Apabila diambil nilai $X_{1}=\{-1,1\} \in R^{2}$ ,penyelesaian akan dilakukan dengan tiga metode.

\section{G. Penyelesian dengan Stepest Descent}

Berdasarkan hal tersebut diperoleh $\nabla Z\left(X_{1}\right)=[-7,1]$ dengan nilai norm $\left\|\nabla Z\left(X_{1}\right)\right\|=\sqrt{50}>\varepsilon$. Karena norm masih lebih besar dari $\varepsilon$, maka iterasi dilanjutkan. Arah pencarian $d_{1}=-\nabla Z\left(X_{1}\right)=[7,-1]$ dan berdasarkan hal tersebut dapat diperoleh $\lambda_{1}=\frac{50}{198}$. Apabila dicari, maka akan diperoleh $X_{2}=\left\{\frac{76}{99}, \frac{74}{99}\right\}$ dengan nilai gradient $\nabla Z\left(X_{2}\right)=[0.070,0.494]$ dan nilai norm $\left\|\nabla Z\left(X_{2}\right)\right\|=0.498>\varepsilon$, maka berdasarkan hal tersebut iterasi dilanjutkan. Dengan cara analog, maka akan diperoleh nilai $d_{2}=-\nabla Z\left(X_{2}\right)=[-0.070,-0.494] \quad$ dan berdasarkan hal tersebut dapat diperoleh $\lambda_{2}=0.49$. Lebih lanjut dengan caa yang sama diperoleh nilai $X_{3}=\{0.732,0.504\}$ dengan gradien $\nabla Z\left(X_{3}\right)=[-0.072,0.008]$ dan 
nilai norm $\left\|\nabla Z\left(X_{3}\right)\right\|=0.07>\varepsilon$. Proses dilanjutkan diperoleh $d_{3}=-\nabla Z\left(X_{3}\right)=[0.072,-0.008]$ serta nilai $\lambda_{3}=0.25$. Berdasarkan hal tersebut diperoleh $X_{4}=\left\{\frac{3}{4}, \frac{1}{2}\right\}$ dengan nilai gradien $\nabla Z\left(X_{2}\right)=[0,0]$ dan $\left\|\nabla Z\left(X_{2}\right)\right\|=0<\varepsilon$. Berdasarkan hal tersebut iterasi berhenti dan solusi numeriknya juga merupakan solusi analitik.

\section{H. Penyelesian dengan Newton}

Diambil $X_{1}=\{-1,1\} \in R^{2} \quad$ Berdasarkan hal tersebut diperoleh $\nabla Z\left(X_{1}\right)=[-7,1]^{t}$ dengan $\left\|\nabla Z\left(X_{1}\right)\right\|=\sqrt{50}>\varepsilon$ dan iterasi dilanjutkan. Lebih lanjut dibentuk matrik Hessian $\quad H\left(X_{1}\right)=\left[\begin{array}{ll}4 & 0 \\ 0 & 2\end{array}\right] \quad$ dan $H\left(X_{1}\right)^{-1}=\left[\begin{array}{cc}\frac{1}{4} & 0 \\ 0 & \frac{1}{2}\end{array}\right]$. Berdasarkan hal tersebut $-H\left(X_{1}\right)^{-1} \nabla Z\left(X_{1}\right)=\left[\frac{7}{4}, \frac{1}{2}\right] \quad$ sehingga diperoleh nilai $X_{2}=\left\{\frac{3}{4}, \frac{3}{2}\right\}$ dengan nilai gradien $\nabla Z\left(X_{2}\right)=[0,2]^{t} \quad$ dan $\left\|\nabla Z\left(X_{2}\right)\right\|=2>\varepsilon \quad$ sehingga $\quad$ iterasi dilanjutkan. Dengan langkah yang sama diperoleh nilai $-H\left(X_{2}\right)^{-1} \nabla Z\left(X_{2}\right)=[0,-1]^{t} \quad$ serta $X_{3}=\left\{\frac{3}{4}, \frac{1}{2}\right\} \quad$ dengan $\quad\left\|\nabla Z\left(X_{3}\right)\right\|=0<\varepsilon$ sehingga iterasi berhenti. Berdasarkan hal tersebut solusi numerik dengan Newton adalah $\quad X_{3}=\left\{\frac{3}{4}, \frac{1}{2}\right\} \quad$ yang sekaligus merupakan solusi analitik.

\section{Penyelesian dengan Stepest Descent Terinduksi Newton}

Diambil $X_{1}=\{-1,1\} \in R^{2} \quad$ Berdasarkan hal tersebut diperoleh $\nabla Z\left(X_{1}\right)=[-7,1]^{\prime}$ dengan $\left\|\nabla Z\left(\overline{X_{1}}\right)\right\|=\sqrt{50}>\varepsilon$. Berdasarkan hal tersebut iterasi dilanjutkan dan dengan langkah analog diperoleh $\lambda_{1}=\frac{47}{51}$ dan nilai $X_{2}=\{0.612,1.460\}$ dengan nilai gradien $\nabla Z\left(X_{2}\right)=[-0.552,1.92]^{t}$ dan nilai norm $\left\|\nabla Z\left(X_{1}\right)\right\|=1.997>\varepsilon$. Lebih lanjut diperoleh nilai $\quad \lambda_{2}=0.96$ dan $\quad X_{3}=\{0.612,0.5\}$ dengan nilai norm $\left\|\nabla Z\left(X_{3}\right)\right\|=0.552>\varepsilon$.

Kemudian diperoleh $\lambda_{3}=-1_{\text {dan }}$ $X_{4}=\left\{\frac{3}{4}, \frac{1}{2}\right\}$ dengan $\quad\left\|\nabla Z\left(X_{4}\right)\right\|=0<\varepsilon$ sehingga iterasi stop. Solusi numerik dengan metode ini identik dengan solusi analitik.

\section{Penutup}

Dari penelitian yang telah dilakukan, terdapat beberapa hal yang dapat disimpulkan:

1. Dalam suatu masalah optimisasi dua variabel tanpa kenda dengan nilai awal tertentu $\bar{X}_{1}$, solusi numerik Stepest Descent akan menghasilkan solusi yang sama dengan Newton, dan dalam langkah iterasi yang sama. Dalam hal yang tertentu pula solusi numerik ini identik dengan solusi analitik pada masalah optimisasi yang dibahas dalam makalah ini. 
2. Dalam nilai awal tertentu $X_{1}$ dan dalam suatu masalah optimisasi, solusi numerik yang dihasilkan oleh metode Stepest Descent terinduksi Newton akan menghasilkan nilai yang sama dengan solusi yang dihasilkan oleh kedua metode di atas meskipun memerlukan iterasi yang lebih panjang. Hal ini dikarenakan nilai $d_{k}$ pada metode Stepest Descent diinduksi dengan $d_{k}=-H\left(X_{k-1}\right)^{-1} \nabla Z\left(X_{k-1}\right)$

3. Adakalanya metode Stepest Descent lebih baik dari Newton dan hal ini dapat dilihat pada contoh kedua yakni dengan soal yang sama seperti contoh satu, namun titik awal $X_{1}$ yang berbeda.

4. Dari contoh dua, metode Stepest Descent terinduksi membutuhkan iterasi yang lebih panjang dari dua metode sebelumnya. Hal ini dikarenakan adanya induksi dari Newton kepada Stepest Descent untuk menggantikan arah pencarian $d_{k}$ pada Stepest Descent

\section{UCAPAN TERIMA KASIH}

Ucapan terima penulis sampaikan kepada Universitas Muhammadiyah Tangerang atas segala dukungan sehingga paper ini dapat terselesaikan.

\section{DAFTAR PUSTAKa}

[1] Rinaldi Munir, Metode numeric, Bandung: Informatika, 2008.

[2] Salmah. Diktat Optimisasi. Yogyakarya: FMIPA UGM, 2011.
[3] Howard Anton, Aljabar Linier, Penerjemah Pantur Silaban, Jakarta: Erlangga, 1991.

[4] Edwin K. P. Chong, An Introduction to Optimization, USA: John Wiley \& Sons, Inc. 2001.

[5] S. Bazaraa. Mochtar, Nonlinear Programming Theory and Algorithms, London: Willey Interscience, 2006.

[6] Yoshikazu Sawaragi, Theory of multiobjective optimization, London: Academic Press Inc. 1985.

[7] Rukmono Budi Utomo, (2016, Mei), Materi Ajar Metode Numerik FKIP $U M T$, http://www.fkip.umt.ac.id/download s.

\section{Riwayat Hidup Penulis}

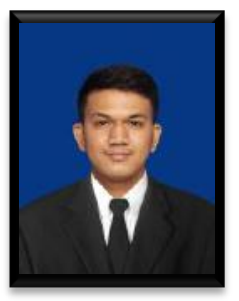

Rukmono Budi Utomo, M.Sc. Lahir di Tangerang 26 September 1991. Penulis merupakan alumnus S1 Matematika Undip (2013), S2 Matematika UGM (2015) dan sekarang selain bekerja sebagai Dosen di Prodi Pendidikan Matematika UMT, Penulis juga mahasiswa program Doktoral Matematika ITB.Nama Penulis dilengkapi dengan gelar. 